\title{
Experimental Study on Action Learning of Different Visual Teaching Methods in Wushu
}

\author{
Qisheng Zhao ${ }^{1}$, Yanyan $\mathrm{Xu}^{1 *}$, Yang Liu $^{2}$ and Jie Chang ${ }^{1}$ \\ ${ }^{1}$ Dehong teachers College, Institute of Physical Education, 678400 Mang shi, Yunnan \\ ${ }^{2}$ Nanchang Normal University, Institute of Physical Education, 330032 Nanchang, Jiangxi
}

\begin{abstract}
Wushu course is a basic content in physical education teaching in colleges and universities. The teaching content of Wushu course is mainly routine teaching. Because Wushu routine is composed of many individual movements, the direction, route, rhythm and body posture are complicated and different from the students' daily activities and other sports teaching materials, many students feel that Wushu is "difficult to learn" and "forget quickly ". In order to overcome the phenomena of "difficult to teach "," difficult to learn" and "forget quickly ", we must deeply study the teaching methods in order to improve the teaching effect of martial arts. Demonstration teaching method is the main teaching method used in Wushu teaching, and it is also one of the effective ways to improve the teaching effect of Wushu. As multimedia teaching is more and more used in teaching, demonstration teaching method also has more new teaching methods. [1] This paper analyzes the effect of martial arts teachers in the teaching process through the experimental study of three classes in the martial arts curriculum of physical education major in Dehong Teachers College. In order to study the teaching effect of different intuitive teaching methods in martial arts class.
\end{abstract}

\section{Introduction}

Wushu is an important content of general physical education teaching in colleges and universities. The method of Wushu teaching is always based on intuitive teaching method, but in the teaching of Wushu movements, according to the different levels of students, different demonstration methods and whether different demonstration methods have the same effect on students' learning movements are rare. In order to further understand the effect of different intuitive teaching methods on students' learning movements, this study intends to carry out experimental research in this respect. In martial arts teaching, the traditional teaching mode and modern technology teaching means are organically combined to make students change from passive acceptance of knowledge to self-learning and selfdevelopment which provides a certain theoretical reference for exploring different martial arts teaching methods.

\footnotetext{
* Corresponding author: zhaoqisheng1119@163.com
} 


\section{Research methods and subjects}

\subsection{Research subjects}

A total of 60 students who had not been exposed to martial arts, had normal intelligence, had good health and were willing to participate in the experiment were sampled from three classes of martial arts courses in physical education major of Dehong Teachers College.

\subsection{Research methods}

\subsubsection{Documentation}

Search the database of Chinese periodicals through the Internet, read and verify the number of action demonstration, multimedia video, and related documents of action demonstration teaching, and related books and periodicals, provide theoretical support and practical guarantee for the research of this subject, sum up and sum up the arguments.

\subsubsection{Interviews}

Interview the physical education teachers of our school (3 qualified teachers who have been on the third way of martial arts primary long fist), the demonstration method used in the teaching of martial arts primary long fist, and the degree to which the students master the main points of action. In a class, we have a preliminary understanding for the content of martial arts teaching and teaching time.

\subsubsection{Experimental methods}

Select three classes, make sure that the students in each class have never been exposed to the course before the experiment, select 20 students from each class, and three groups as control group (the first class action demonstration teaching, the second class video demonstration teaching, The third class video combined with action demonstration teaching), the first stage of primary long fist teaching in outdoor stadium.

\section{Results and analysis}

\subsection{Analysis of the results of action demonstration teaching}

From the number of action demonstration in Table 1, we can see that when the students in the first experimental group demonstrate the action to 8 times, the students remember the action, and in the course of teaching, the teachers adopt the complete model law, decompose the model law and explain the model law. The teacher first carries on the complete demonstration in the demonstration, causes the student to establish a complete technical concept, causes it to form the movement appearance preliminarily in the mind. Then decompose the demonstration teaching. In teaching, multiple horizontal teams are used. The teacher's demonstration position is always in the right front (or left front) of the forward direction of the team, and the demonstration position is adjusted in time according to the change of the action direction. In demonstration speed, using slow demonstration can 
make students understand action information more clearly. See Figure 1 for the data analysis of the first experimental group.

Table 1 .First experimental group

\begin{tabular}{ccccc}
\hline $\begin{array}{c}\text { Number of demonstrations } \\
\text { (times) }\end{array}$ & Fifth & Sixth & Seventh & Eighth \\
\hline Memory level (person) & five & eleven & eighteen & twenty \\
\hline
\end{tabular}

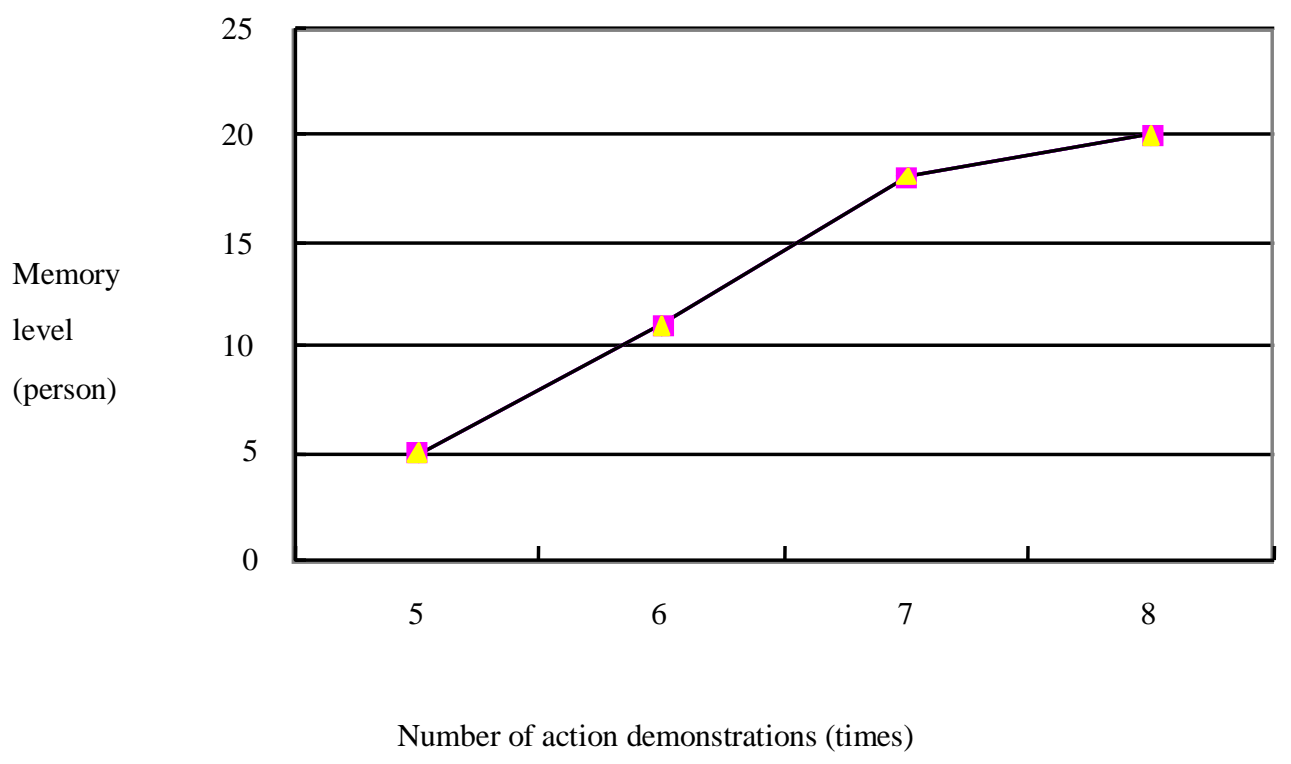

Figure 1 Data analysis of the first experimental group

\subsection{Analysis of video teaching results}

As can be seen from the number of video demonstration teaching and the number of students' memory in Table 2, Video demonstration is a positive, complete action demonstration. Teachers and students stand opposite for a positive demonstration. Positive demonstration helps to show the main points of the teacher's positive action, But because the positive demonstration is the the relative standing of teachers and students, it is not conducive to the movement of the direction. See Figure 2 for the second experimental group. 
Table 2. Second experimental group

\begin{tabular}{cccccc}
\hline $\begin{array}{c}\text { Number of } \\
\text { broadcasts (times) }\end{array}$ & Fifth & Sixth & Seventh & Eighth & Ninth \\
\hline $\begin{array}{c}\text { Memory level } \\
\text { (person) }\end{array}$ & three & seven & twelve & seventeen & twenty \\
\hline
\end{tabular}

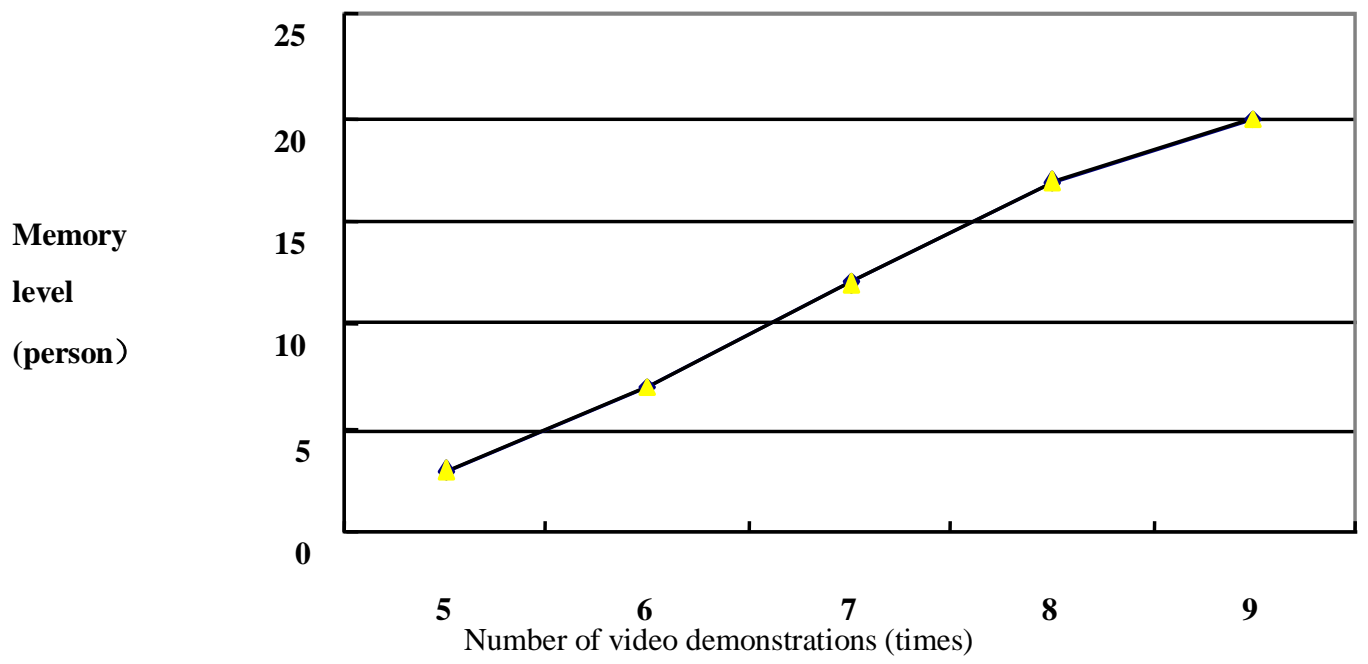

Figure 2 Data broken line diagram of the second experimental group

\subsection{Analysis of the results after the combination of action demonstration teaching and video teaching}

First watch video demonstration teaching, so that students have a preliminary impression of the direction and essentials of action. [2] In this process reflects a problem, students master the initial points of action is relatively fast, but always reverse the direction of the action. Next, the teacher carries on the action demonstration teaching, and explains the reverse problem in the process of watching the video self-study, the student can master the action quickly. [3] The students of the third experimental group had a higher degree of mastery of the primary long fist than the students of the first two experimental groups. See Figure 3 for specific data origami plots for the third experimental group. 


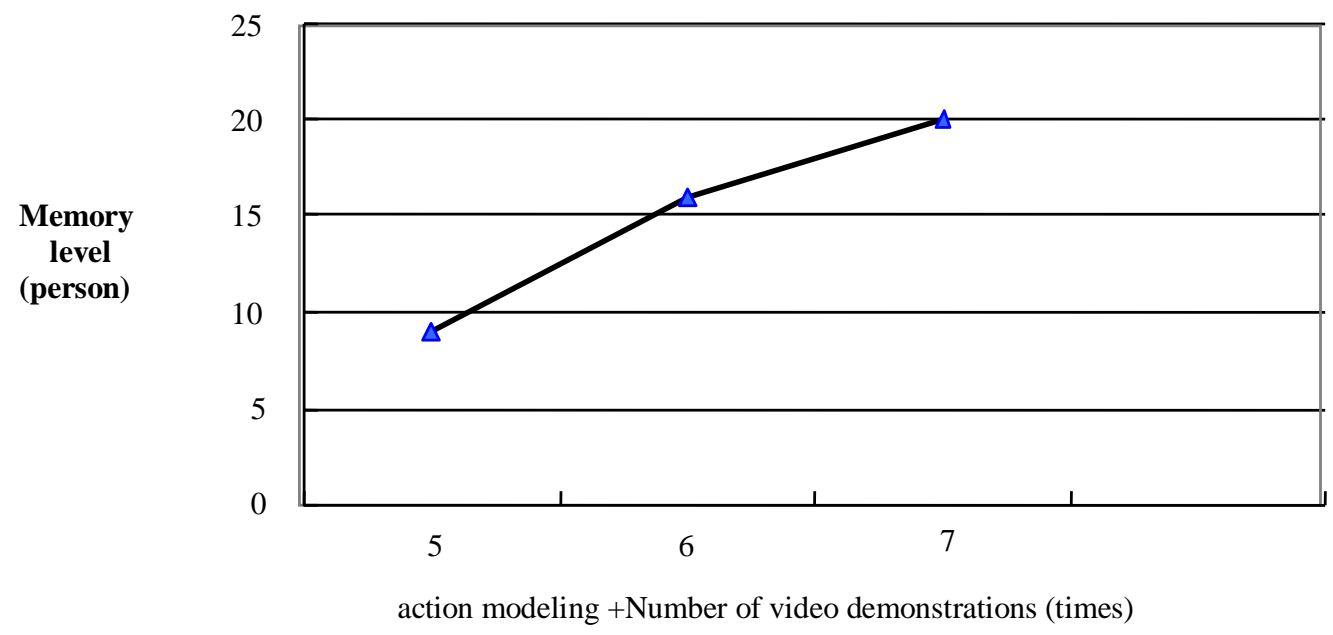

Figure 3 Data broken line diagram of the third experimental group

\subsection{Comparison of three different demonstration teaching methods}

The movement demonstration teaching is better in the martial arts movement direction. From Table 1, we can see that although action demonstration teaching is an effective means in intuitive teaching, it plays a multiplier role in students' technical mastery and motor skills formation, but it is an activity in which teachers and students participate to pay more attention to teaching activities.

Video demonstration teaching deepens students' memory of martial arts movements. From the situation of memory degree in Table 2 and Table 1, it is obvious that no middle school students in Table 1 have fast memory movements. In the experiment, students watch video to learn the first paragraph of primary long fist, always reverse the action in the direction. Although video teaching can cultivate students' abstract thinking ability, train left brain and develop right brain, we should pay attention to direction and route in learning martial arts movements. Therefore, we should pay attention to the direction of action in video teaching which can effectively carry on the martial arts movement study.

Video demonstration teaching plus action demonstration teaching can make students familiar with the action first, and then according to the teacher's action demonstration teaching can better learn the action. From Table 3, we can see that the combination of action demonstration teaching and video teaching can effectively learn martial arts movements. When students first watch the video, they have a preliminary impression of the movements, and then when teachers carry out action demonstration teaching, Students can quickly remember the main points, directions and routes of the movements. It improves the utilization rate of classroom effective time, increases the amount of information transmitted in teaching, expands the scope of knowledge, and broadens the students' horizons and ideas. 
Table 3. Third experimental group

\begin{tabular}{cccc}
\hline $\begin{array}{c}\text { Number of broadcasts+Number of } \\
\text { demonstrations (times) }\end{array}$ & Third+Second & Second+First & First+First \\
\hline Memory level (person) & nine & sixteen & twenty \\
\hline
\end{tabular}

\section{Countermeasures}

\subsection{Combination of Multimedia Technology Teaching and Traditional Wushu Teaching}

Multimedia technology teaching is not used in martial arts teaching. Before learning the new action, by watching the whole set of demonstration actions, students can have a more comprehensive understanding of the action name, movement direction and action line. Then watch again with slower speed, let students understand the action image, structure and action details, and further strengthen memory. Multimedia teaching improves the utilization rate of effective time in class, increases the amount of information transmitted in teaching, and broadens students' vision and ideas. It can also make students master technical movements faster and more accurately and understand the main points of action. [4]

Traditional teaching means and multimedia teaching means complement each other in the whole teaching process. Multimedia teaching, as a new teaching means, has its own many advantages and can enrich and make up for the defects in traditional teaching. But it does not mean that everything is superior to the traditional teaching means, and its own defects need to be compensated by the traditional teaching means. Sports workers in colleges and universities should consciously infiltrate and integrate the two teaching methods.

\subsection{Innovative Development of Model Teaching Method in Wushu Teaching}

Multimedia teaching enriches the content of demonstration teaching method, and its application solves some problems of action demonstration in martial arts teaching. In the traditional teaching mode, due to the lack of professional development of teachers, the demonstration ability and the standardization of action are lacking, and with the increase of age, some of the ability to empty, flip or complete high-speed actions decreases. Therefore, teachers will try to avoid these actions and choose the teaching content according to their own preferences. [5] These directly affect the enthusiasm of students to learn and the degree of mastery of action. Using multimedia teaching, teachers can use multimedia teaching at any time, teachers can stop the action process at any time, show the key points and difficulties, especially some technical details of air movements, and help students to establish a more comprehensive and detailed action representation. The relevant courseware can help students understand the principle and physiological basis of action and raise perceptual knowledge to the height of rationality. The use of multimedia teaching can span time and space, and some materials can be reintegrated to establish a dialogue between the past, present and future in the functional network, adding a refreshing element to the demonstration teaching method. [6] 


\subsection{Issues to be noted in the application of the Model Law on Teaching}

The material of martial arts teaching is the attack and defense action. Therefore, combining the attack and defense characteristics of the action to explain the demonstration in the teaching can not only deepen the students' understanding and mastery of the action, but also arouse the students' interest in learning martial arts. Mobilize the enthusiasm of learning. [7]

Action demonstration is the main means for students to obtain action information. If the purpose of demonstration is clear and the demonstration method is correct, the students will not have visual disorder and improve the teaching efficiency. Therefore, teachers should choose reasonable demonstration methods according to teaching contents. [8] In teaching, combined with the characteristics of action and teaching emphasis, flexible use of a variety of demonstration methods, pay attention to the combination of complete demonstration and decomposition demonstration, slow demonstration and constant speed demonstration.

\section{Conclusions and recommendations}

\subsection{Conclusions}

Although the traditional demonstration teaching quickly enables students to master movements, it does not raise the enthusiasm of students to learn martial arts. Students rely more on traditional teaching methods. According to the first group of experiments, the teacher's eighth demonstration teaching.

The advantage of video demonstration teaching is that students can have a preliminary impression of learning movements, arouse the enthusiasm of students to learn martial arts, and find that the second group has been used 9 times through experiments, and the students have mastered the main points of action. However, in teaching, students master action slower than action demonstration teaching, because students cannot master the direction of action, the route is not clear.

With the combination of action demonstration teaching and video demonstration teaching, students can quickly master the essentials and routes of action. According to the experimental comparison of the third group, the students can easily master the technical action essentials after sharing three demonstrations and two videos. Through their own understanding and teacher's action demonstration can quickly remove the problems that students cannot master.

\subsection{Recommendations}

In order to better apply the model law to physical education, the traditional education model centered on teachers has been changed, and the subjective initiative of teachers and students has been fully mobilized. In the case of multimedia teaching, make full use of modern teaching means to improve the teaching effect. Therefore, in martial arts teaching, the traditional teaching mode and modern technology teaching means want to be combined, so that students from passive acceptance of knowledge to self-learning, self-development. However, in the teaching process, according to the actual teaching conditions. After watching the video, students can discuss and ask questions for further study in the future. [9]

Fund Project: 2020 Yunnan High-level Talents Training Support Program; Funding of Scientific Research Fund of Department of Education, Yunnan Province (2020J0840); Physical education and 
training discipline characteristic team (2020xhxtd10); Dehong teachers College Science Fund Grant Program (XJ202007)

\section{References}

1. Xiao Yaling. A Study on the Influence of Multimedia on the Traditional Teaching Method of Wushu [J]. in Chinese Martial arts science. 2014.08

2. Yan Bao Dong Yuying. Application of Multimedia Technology in Wushu Teaching [J].A Brief Discussion Education and occupation. 2017.08

3. Li Qiang. Action Model Law in Martial Arts Teaching [J].] The Role P. E. Friends. 2004.04

4. Sun Hongxia. Experimental Research on Multimedia Technology in Primary Threeway Long-Fun Course Teaching [D].; and Junior physical education university. 2015.06

5. Liang Dongmei. on the Role of Demonstration Action in Physical Education Teaching[J]. Health vocational education 2004.05

6. Xue Qingyun. Application and Development of Model Teaching Method in Wushu Teaching [J].Journal of Fujian Radio and Television University ,2006.02

7. Zhao Xiaohong. A Preliminary Study on the Demonstration of Wushu [R].Teaching Hubei Sports Science and Technology. 1998.02

8. Li Haoqiang. Application of Model Law in Wushu Teaching [J].] A Brief Discussion Scientific Advice .2016(18)

9. Zhang Feng. A Practical Path to the Reform of Wushu Teaching in[J]. School Journal of Shanghai Institute of Physical Education ,2015.01 